\title{
A new tangential gamma-ray spectrometer for fast ion measurements in deuterium and deuterium-tritium plasmas of the Joint European Torus
}

Nocente, M.; Craciunescu, T.; Gorini, G.; Kiptily, V.; Tardocchi, M.; Braic, V.; Curuia, M.; Dal Molin, A.; Figueiredo, J.; Giacomelli, L.

Total number of authors:

21

Published in:

Review of Scientific Instruments

Link to article, DOI:

$10.1063 / 5.0043806$

Publication date:

2021

Document Version

Peer reviewed version

Link back to DTU Orbit

Citation (APA):

Nocente, M., Craciunescu, T., Gorini, G., Kiptily, V., Tardocchi, M., Braic, V., Curuia, M., Dal Molin, A., Figueiredo, J., Giacomelli, L., lliasova, M., Kazakov, Y., Khilkevitch, E., Marcer, G., Panontin, E., Rigamonti, D., Salewski, M., Shevelev, A., Soare, S., ... Zychor, I. (2021). A new tangential gamma-ray spectrometer for fast ion measurements in deuterium and deuterium-tritium plasmas of the Joint European Torus. Review of Scientific Instruments, 92(4), [043537]. https://doi.org/10.1063/5.0043806

\section{General rights}

Copyright and moral rights for the publications made accessible in the public portal are retained by the authors and/or other copyright owners and it is a condition of accessing publications that users recognise and abide by the legal requirements associated with these rights.

- Users may download and print one copy of any publication from the public portal for the purpose of private study or research.

- You may not further distribute the material or use it for any profit-making activity or commercial gain

- You may freely distribute the URL identifying the publication in the public portal 


\section{A new tangential gamma-ray spectrometer for fast ion measurements in deuterium and deuterium-tritium plasmas of the Joint European Torus}

M. Nocente, ${ }^{1,2, a)}$ T. Craciunescu, ${ }^{3}$ G. Gorini, ${ }^{1,2}$ V. Kiptily, ${ }^{4}$ M. Tardocchi, ${ }^{2}$ V. Braic, ${ }^{3}$ M. Curuia, ${ }^{3}$ A. Dal Molin, ${ }^{1}$ J. Figueiredo, ${ }^{5}{ }^{6}$ L. Giacomelli, ${ }^{2}$ M. Iliasova, ${ }^{7}$ Y. Kazakov, ${ }^{8}$ E. Khilkevitch, ${ }^{7}$ G. Marcer, ${ }^{1}$ E. Panontin, ${ }^{1}$ D. Rigamonti, ${ }^{2}$ M. Salewski, ${ }^{9}$ A. Shevelev, ${ }^{7}$ S. Soare, ${ }^{3}$ V. Zoita, ${ }^{3}$ I. Zychor, ${ }^{10}$ and JET Contributors ${ }^{11, b)}$

1) Department of Physics "G. Occhialini", University of Milano-Bicocca, 20126, Milan, Italy

2) Institute for Plasma Science and Technology, National Research Council, 20125, Milan,

Italy

${ }^{3)}$ Institute of Atomic Physics, Magurele-Bucharest, 077125, Romania

4) Culham Centre for Fusion Energy, Abingdon, OX143EB, United Kingdom

${ }^{5)}$ Instituto de Plasmas e Fusão Nuclear, Instituto Superior Técnico, Universidade de Lisboa, 1049-001, Lisboa, Portugal

6) EUROfusion Consortium, Boltzmannstr.2, Garching, 85748, Germany

7) Ioffe Institute, St. Petersburg, 195021, Russian Federation

${ }^{8)}$ Laboratory for Plasma Physics LPP-ERM/KMS, Brussels, 1000, Belgium

9) Technical University of Denmark, Kgs. Lyngby, 2800, Denmark

${ }^{10)}$ Narodowe Centrum Badan Jadrowych (NCBJ), Otwock-Swierk, 05-400, Poland

11) EUROfusion Consortium, JET, Culham Science Centre, Abingdon, OX143EB, United Kingdom

A new tangential gamma-ray spectrometer has been developed for fast ion measurements in deuterium and deuterium-tritium plasmas of the Joint European Torus (JET). The instrument is based on a $\mathrm{LaBr}_{3} \mathrm{crystal}$ with a photo-multiplier tube and replaces a pre-existing Bismuth Germanate detector, providing enhanced energy resolution and a counting rate capability in the $\mathrm{MHz}$ range. The line of sight is equipped with a $\mathrm{LiH}$ attenuator, which reduces the background due to $14 \mathrm{MeV}$ neutron interactions with the crystal by more than two orders of magnitude and enables the observation of gamma-ray emission from confined $\alpha$ particles in JET deuterium-tritium plasmas. Thanks to its tangential line of sight, the detector can distinguish co- and counter-passing ions. The performance of the instrument is demonstrated by results in recent JET fast ion experiments in deuterium plasmas.

\section{INTRODUCTION}

Among the scientific goals of the forthcoming deuterium-tritium (DT) campaign of the Joint European Torus $(\mathrm{JET})^{1}$ there is the need to increase our understanding of alpha particle physics, mostly in terms of transport and the role alpha particles have in the excitation of fast ion driven instabilities in view of ITER $^{2}$. From the diagnostics side, a number of enhancements has been conducted to improve the alpha particle observational capabilities of $\mathrm{JET}^{3}$, particularly as far as gamma-ray spectrometry is concerned. Here the main interest is in the detection of the $4.44 \mathrm{MeV}$ line from the $\alpha+{ }^{9} \mathrm{Be} \rightarrow \mathrm{n}+{ }^{12} \mathrm{C}^{*}$ reaction ${ }^{4}$, as this emission provides information on the alpha particle energy distribution, as well as its profile ${ }^{5}$.

The main instruments developed for this scope are a gamma-ray camera $(\mathrm{GC})^{6,7}$ and two set of gamma-ray spectrometers (GRS), one vertical (V-GRS) and one tangential (T-GRS). The GC determines the profile of fast ions in general, including $\alpha$ particles in DT, by detecting gamma-ray emission from characteristic nuclear reactions along a set of horizontal and vertical lines of sight

\footnotetext{
a) massimo.nocente@mib.infn.it

b) See the author list of E. Joffrin et al 2019 Nucl. Fusion 59112021
}

deployed in a fan shaped array and with the use of silicon photo-multiplier (SiPMs).

The V-GRS and T-GRS are instead optimized for spectral measurements and have better energy resolution ( $3.5 \%$ compared with $5 \%$ at $\mathrm{E}_{\gamma}=662 \mathrm{keV}$ for the GC), detection efficiency (by a factor $\approx 3$ ) and background suppression capabilities compared with the GC. The GRS detectors also provide a linear conversion between channel and gamma-ray energy within few $\%$ up to $\mathrm{E}_{\gamma}=20$ $\mathrm{MeV}$. For comparison, the GC has a $>30 \%$ non linearity for $\mathrm{E}_{\gamma}>10 \mathrm{MeV}$ due to the use of SiPMs. V-GRS allows choosing among different spectrometers, which are selected depending on the experimental conditions. The most used are a High Purity Germanium $(\mathrm{HpGe})^{8}$ and a $\mathrm{LaBr}_{3}$ detector ${ }^{9,10}$.

T-GRS consists instead of a single spectrometer, which was previously based on a $7.5 \mathrm{~cm} \times 7.5 \mathrm{~cm}$ (diameter $\mathrm{x}$ height) Bismuth Germanate (BGO) scintillator ${ }^{11}$. In order to meet the needs for $\alpha$ particle measurements in DT, mostly in terms of energy resolution and counting rate capabilities, the detector of T-GRS has recently been upgraded to a $\mathrm{LaBr}_{3}$ scintillator and a dedicated neutron attenuator has been built for its line of sight. The tangential line-of sight of T-GRS allows distinguishing coand counter-going particles, which is not possible with vertical geometries. This is crucial for the reconstruction of velocity distributions at JET and ITER ${ }^{4,12}$. 


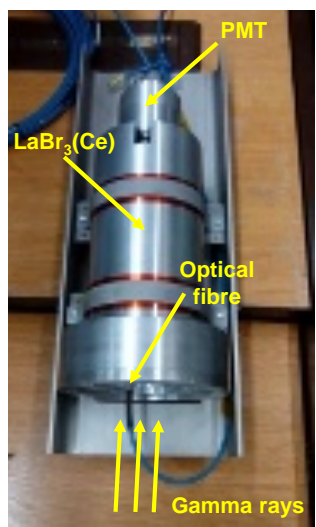

FIG. 1. $\mathrm{LaBr}_{3}(\mathrm{Ce})$ detector developed for JET. The figure shows the location of the 3 " 6 " $\operatorname{LaBr}_{3}(\mathrm{Ce})$ crystal wrapped with mu-metal, the photomultiplier tube (PMT) and the direction of incidence of the gamma-ray radiation. An optical fiber provides a reference signal for control and monitoring purposes.

In this paper we describe the properties of the upgraded T-GRS. Section II presents the main parameters of the detector and illustrates its complementarity with the HpGe V-GRS. The T-GRS line of sight is discussed in section III. Finally, example of measurements from recent fast ion experiments in JET deuterium plasma are provided and compared with observations by the $\mathrm{HpGe}$ V-GRS.

\section{A NEW $\mathrm{LaBr}_{3}(\mathrm{Ce})$ SPECTROMETER FOR JET}

The T-GRS is based on a 3"x6" (diameter x length) cylindrical $\mathrm{LaBr}_{3}$ scintillator developed by St Gobain (see figure 1) and replaces a former $7.5 \mathrm{~cm} \mathrm{x} 7.5 \mathrm{~cm}$ Bismuth Germanate (BGO) spectrometer ${ }^{11}$. The upgrade of the BGO was required predominantly to enable measurements at $\mathrm{MHz}$ counting rates, such as those expected from the $14 \mathrm{MeV}$ neutron background in DT plasmas ${ }^{13}$ or in runaway electron experiments in D plasmas. Another need was to distinguish lines separated by $\approx 100$ $\mathrm{keV}$ in the $\mathrm{MeV}$ range, for example those arising from radio-frequency heating in hydrogen plasmas with ${ }^{3} \mathrm{He}^{14}$. Both requirements had to be met without compromising the detection efficiency, which had to be comparable with that of the BGO.

The dimensions of T-GRS are the same as those of the $\mathrm{LaBr}_{3}$ based V-GRS. A mu-metal wrapping with a thickness of a $2 \mathrm{~mm}$ provides shielding from the residual magnetic field at the location of the detector, which sits about $23 \mathrm{~m}$ from the centre of the plasma on Octant 8. The scintillation light resulting from the interaction of gammarays with the detector is collected by a R10233 Hamamatsu photomultiplier tube (PMT) with 3.5" diameter.

Each electric pulse from the PMT is digitized when its amplitude exceeds a threshold set by the user. A $400 \mathrm{MHz}, 14$ bit, Advanced Telecommunications Com- puting Architecture (ATCA) based digitization system ${ }^{15}$ similar to that adopted for the V-GRS $\mathrm{LaBr}_{3}$ detector is used for T-GRS. This records individual waveforms and their time stamp, which tells when each gamma-ray interaction occurred. A fitting algorithm with pile-up rejection capabilities ${ }^{10}$ is adopted for off-line processing of the waveforms and to build their pulse height spectrum and counting rate in arbitrary time and energy windows for each JET discharge. A control and monitoring (C\&M) system $^{9}$ based on a LED source and a bundle of fibers that guides the light to the detector provides a reference signal, which is used to monitor and correct for possible gain shifts that may occur during the discharge. The energy resolution (expressed as the ratio between the full width at half maximum and the centroid of the peak) measured at JET is $3.5 \%, 2.4 \%$ and $2.2 \%$ at the energies of the gamma-ray emission from the ${ }^{137} \mathrm{Cs}$ and ${ }^{60} \mathrm{Co}$ calibration sources, i.e. $\mathrm{E}_{\gamma}=662 \mathrm{keV}, 1173 \mathrm{keV}$ and 1333 $\mathrm{keV}$, respectively. Assuming that the $1 / \sqrt{E_{\gamma}}$ statistical contribution to the energy resolution is dominant, these values extrapolate to better than $1.5 \%$ for $\mathrm{E}_{\gamma}>2.5 \mathrm{MeV}$, which makes the detection of lines separated by few hundreds keV possible in this energy range. For comparison, the former BGO spectrometer had a typical energy resolution around $10 \%$ at $662 \mathrm{keV}$, i.e. about three times worse than T-GRS, but a better full peak $\left(\epsilon_{P}\right)$ detection efficiency of $42 \%$ at $\mathrm{E}_{\gamma}=4.44 \mathrm{MeV}$, which compares with $24 \%$ for $\mathrm{LaBr}_{3}$. The total detection efficiency $\left(\epsilon_{T}\right)$ is similar, $87 \%$ for BGO and $93 \%$ for $\mathrm{LaBr}_{3}$. In terms of time properties, the decay time of each pulse from a gamma-ray interaction is about $20 \mathrm{~ns}$ in T-GRS, opening up to measurements at counting rates up to a few $\mathrm{MHz}^{10}$, and compares with $300 \mathrm{~ns}$ for the BGO.

T-GRS also provides complementary information when the HpGe detector is used as V-GRS, particularly when the detection of $\mathrm{E}_{\gamma}>10 \mathrm{MeV}$ gamma-rays born from fusion reactions ${ }^{16,17}$ is of interest (see section IV below). Figure II compares the total and full peak detection efficiencies for T-GRS and the HpGe over a wide energy range between $1 \mathrm{MeV}$ and $15 \mathrm{MeV}$. We find that $\epsilon_{T}$ is always larger by at least $50 \%$ for T-GRS compared with $\mathrm{HpGe}$, with $\epsilon_{P}$ being up to a factor 3 higher in the $\mathrm{E}_{\gamma}>$ $10 \mathrm{MeV}$ range. T-GRS is therefore particularly useful to detect high energy, fusion born gamma-rays in discharges where the HpGe experience limitations.

\section{TANGENTIAL LINE OF SIGHT}

Another important feature of T-GRS is its tangential line of sight $(\mathrm{LOS})^{18}$, shown in figure III, and complementary to that of V-GRS. The LOS has a double pass through the magnetic axis and crosses the plasma centre $\approx 30 \mathrm{~cm}$ below the magnetic axis for most discharges. The angle between the line of sight and the toroidal magnetic field in the plasma core is $\approx 50^{\circ}$.

As $\mathrm{LaBr}_{3}$ is sensitive to the interaction of $14 \mathrm{MeV}$ 


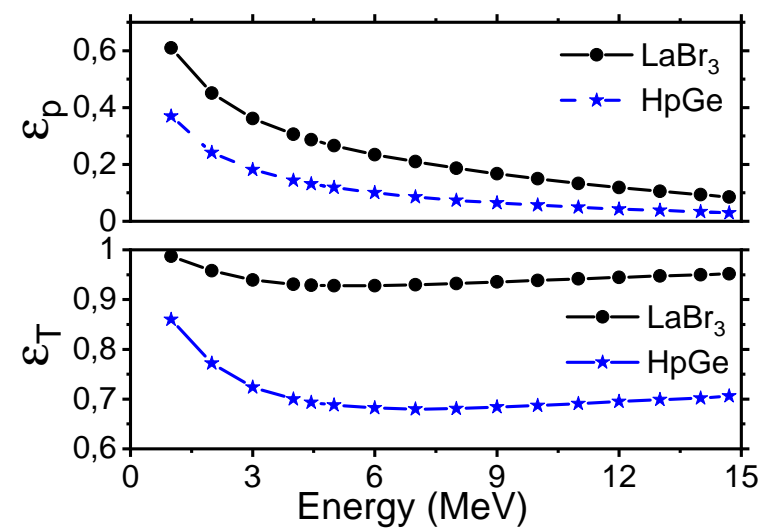

FIG. 2. Full energy peak ( $\epsilon_{P}$, top) and total $\left(\epsilon_{T}\right.$, bottom) efficiencies for the $\mathrm{LaBr}_{3}$ and HpGe detectors at JET as a function of the gamma-ray energy in the range $1 \mathrm{MeV}$ to 15 $\mathrm{MeV}$.

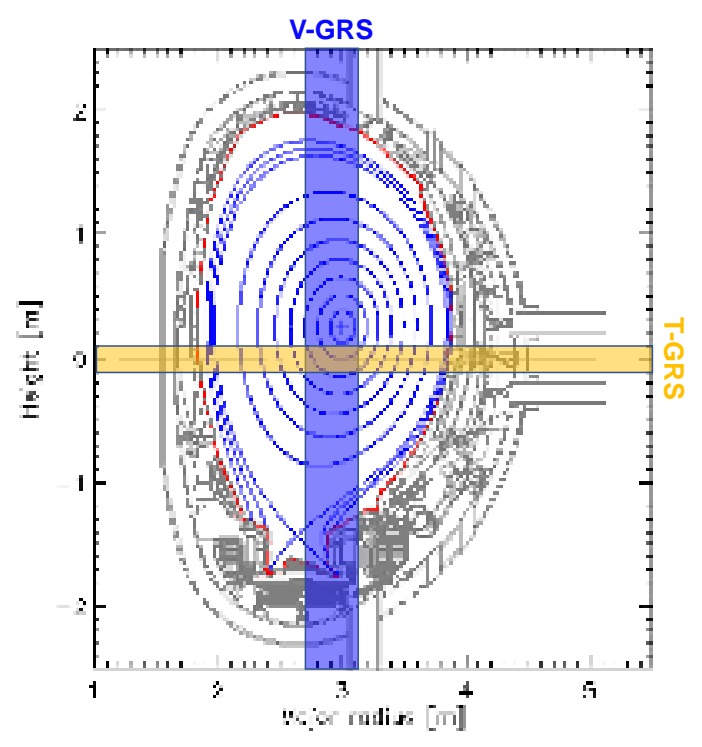

FIG. 3. Line of sight of the vertical (V-GRS) and tangential (T-GRS) gamma-ray detectors at JET in the poloidal plane. The magnetic equilibrium is obtained from JET discharge \#95680.

neutrons ${ }^{13}$, a carefully studied attenuator based on $\mathrm{LiH}$ has been designed and built for the T-GRS LOS. The design has been driven by MCNP simulations, with additional constraints provided by existing mechanical components along the LOS. The $\mathrm{LiH}$ attenuator is made of two fixed disks, with a total length of $66 \mathrm{~cm}$, and a movable one, which is $30 \mathrm{~cm}$ long. When the full length of the attenuator is used, corresponding to a total length of 96 $\mathrm{cm}, 14 \mathrm{MeV}$ DT fusion born neutrons are attenuated by a factor $\approx 275$ according to MCNP calculations ${ }^{18}$, while $\mathrm{MeV}$ range gamma-rays are reduced by a factor $\approx 2-3$ at most, making gamma-ray measurements possible up to neutron rates of some $10^{18} \mathrm{n} / \mathrm{s}$. Without $\mathrm{LiH}$, the detector signal would be overwhelmed by $14 \mathrm{MeV}$ neutrons already at rates of a few $10^{16} \mathrm{n} / \mathrm{s}$, which correspond to a high performance deuterium plasma at JET. The attenuation provided for $2.5 \mathrm{MeV}$ neutrons from $\mathrm{d}+\mathrm{d}$ reactions is $\approx 900$. A detailed description of the attenuator design and engineering is given in reference ${ }^{18}$. The choice of $\mathrm{LiH}$ as the attenuator material is motivated also by the fact that neutrons are unlikely to generate additional gammarays when they interact in this material. This is predominantly due to the absence of ${ }^{12} C$, which is abundant, for instance, in the more conventional polyethylene, and which generates $4.44 \mathrm{MeV}$ gamma-rays due to $\mathrm{n}+{ }^{12} \mathrm{C}$ inelastic scattering.

The availability of a tangential LOS is important for experiments on radio-frequency (RF) heating, especially for off-axis resonances. In this case, fast ion generation occurs away from the plasma core and the resulting gamma-ray emission cannot be measured with V-GRS. Differences between the spectra observed with T-GRS and V-GRS can therefore help at understanding the spatial position of the fast ion generation and complement more detailed information coming from the JET gammaray camera $(\mathrm{GC})$. This will be useful particularly in DT, when the GC will experience significant limitations at neutron rates $>10^{17} \mathrm{n} / \mathrm{s}$, mostly because of the insufficient neutron shielding of this instrument ${ }^{19}$. In terms of fast ion velocity space capability, the LOS of T-GRS and V-GRS are also complementary. As shown in ${ }^{20}$, the high and low energy tails of the shape of gamma-ray lines measured along the T-GRS LOS is mostly determined by co- and counter-passing energetic ions, while the contribution of trapped fast ions in the same spectral region is larger for lines measured by V-GRS. The combination of T-GRS and V-GRS thus makes it possible to separate the dynamics of passing and trapped fast ions by line spectral shape analysis, at least for those scenarios when the fast ion Doppler broadening of the gamma-ray line compares or exceeds the broadening from the instrumental resolution, for example for the $\alpha+{ }^{9} \mathrm{Be} \rightarrow \mathrm{n}+{ }^{12} \mathrm{C}^{*}$ reaction in DT plasmas or, more generally, when the fast ion populations have predominantly $\mathrm{MeV}$ range energies. The integrated data analysis of T-GRS and V-GRS could even allow measurements of alpha-particle velocity distribution functions by velocity-space tomography ${ }^{12}$.

\section{EXAMPLE OF MEASUREMENTS}

T-GRS has been used in the most recent deuterium campaign at JET and has provided useful information particularly in experiments on fast ion generation by RF heating. Figure IV shows an example of measurements from a recent experiment on the the so-called ' 3 ion scenarios ${ }^{14,21}$ in a plasma of deuterium and ${ }^{3} \mathrm{He}$ at relative concentrations of $50 \%$ and $25 \%$, respectively ${ }^{22}$. In this experiment, RF heating accelerates a beam of deuterium ions up to the $\mathrm{MeV}$ range in a narrow region around the plasma core. The deuterium energy distribution is controlled by the ratio between the neutral 

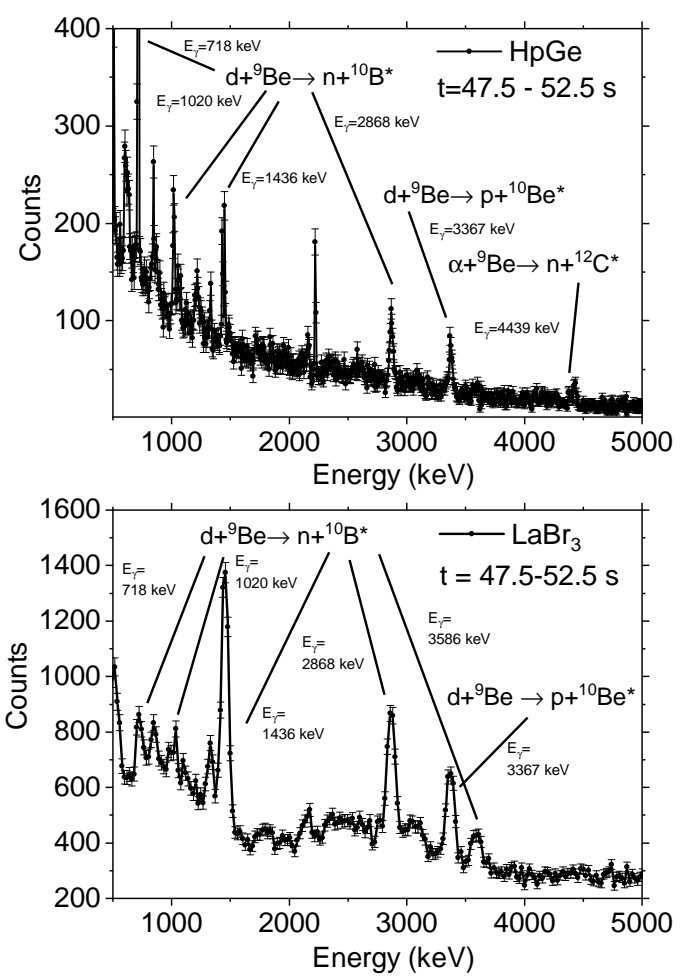

FIG. 4. Gamma-ray spectrum measured by the vertical HpGe (top) and tangential $\mathrm{LaBr}_{3}$ (bottom) detectors for JET discharge \#95680 in the time window $\mathrm{t}=47.5$ to $52.5 \mathrm{~s}$. Lines born from the $\mathrm{d}+{ }^{9} \mathrm{Be} \rightarrow \mathrm{n}+{ }^{10} \mathrm{~B}^{*}$, $\mathrm{d}+{ }^{9} \mathrm{Be} \rightarrow \mathrm{p}+{ }^{10} \mathrm{Be}^{*}$ and $\alpha+{ }^{9} \mathrm{Be} \rightarrow \mathrm{n}+{ }^{12} \mathrm{C}^{*}$ reactions are indicated.

beam injection (NBI) and RF power and modifies the reactivity of the $\mathrm{d}+{ }^{3} \mathrm{He} \rightarrow \alpha+\mathrm{p}$ fusion reaction. In this way, fusion born $\alpha$ particles are generated at rates up to $\approx 2 \times 10^{16} \alpha / \mathrm{s}$ and can be studied without the difficulties of a full scale DT experiment, particularly those arising from the intense $14 \mathrm{MeV}$ neutron background. As both deuterons and $\alpha$ particles are generated in the $\mathrm{MeV}$ range, we expect to observe lines from the $\mathrm{d}+{ }^{9} \mathrm{Be} \rightarrow \mathrm{n}+{ }^{10} \mathrm{~B}^{*}, \mathrm{~d}+{ }^{9} \mathrm{Be} \rightarrow \mathrm{p}+{ }^{10} \mathrm{Be}^{*}$ and $\alpha+{ }^{9} \mathrm{Be} \rightarrow \mathrm{n}+{ }^{12} \mathrm{C}^{*}$ gamma-ray emission reactions. In the experiment, the HpGe detector was chosen as the VGRS since the emission from the plasma was sufficiently intense to obtain a good measurement statistics when integrating data for 5 seconds. A comparison of the $\mathrm{V}$ GRS and T-GRS spectra for JET discharge \#95680 in the time window $\mathrm{t}=47.5 \mathrm{~s}$ to $52.5 \mathrm{~s}$ is shown in figure IV.

Most of the lines seen by the HpGe are also observed by the T-GRS. As expected, HpGe has a superior energy resolution, but the statistics is up to three times better for T-GRS. This is because of the higher T-GRS detection efficiency and the fact that the T-GRS line of sight crosses the plasma centre twice at a comparable distance of the detector from the plasma centre $(\approx 23 \mathrm{~m})$. Some differences are seen between the two spectra. For instance, the $4.44 \mathrm{MeV}$ emission from the $\alpha+{ }^{9} \mathrm{Be} \rightarrow \mathrm{n}+{ }^{12} \mathrm{C}^{*}$ reaction is observed by the $\mathrm{HpGe}$, but not by T-GRS. This is because, in this experiment, $\alpha$ particle generation occurs predominantly in $\mathrm{a} \approx 10 \mathrm{~cm}$ circular region around the magnetic axis, as suggested by the $\mathrm{GC}^{23}$, and this area is barely intercepted by the LOS of T-GRS. Another difference is the $\mathrm{E}_{\gamma}=3586 \mathrm{keV}$ line from the $\mathrm{d}+{ }^{9} \mathrm{Be} \rightarrow \mathrm{n}+{ }^{10} \mathrm{~B}^{*}$ reaction, which is hardly seen by the $\mathrm{HpGe}$, because of its lower detection efficiency. Despite this, using the HpGe in the vertical LOS makes clear gamma-ray Doppler broadening measurements possible for many lines and the HpGe/T-GRS combination is therefore, generally, the preferred option when gamma-ray fluxes and the neutron background allow. The use of $\mathrm{LaBr}_{3}$ as the V-GRS is available for all the other scenarios.

Figure V shows the same T-GRS spectrum of figure IV, but in logarithmic scale and in an energy range up to $\mathrm{E}_{\gamma}=20 \mathrm{MeV}$. We note that, besides the already mentioned lines from the $\mathrm{d}+{ }^{9} \mathrm{Be} \rightarrow \mathrm{n}+{ }^{10} \mathrm{~B}^{*}$ and $\mathrm{d}+{ }^{9} \mathrm{Be} \rightarrow \mathrm{p}+{ }^{10} \mathrm{Be}^{*}$ reaction in the range $\mathrm{E}_{\gamma}=1 \mathrm{MeV}$ to $5 \mathrm{MeV}$, there is a clear structure between $\mathrm{E}_{\gamma}=10 \mathrm{MeV}$ and $20 \mathrm{MeV}$ and that exceeds the background in this region. This is due to $16.4 \mathrm{MeV}$ gamma-rays born from the $\mathrm{d}+{ }^{3} \mathrm{He} \rightarrow \gamma+{ }^{5} \mathrm{Li}$ reaction, that occurs together with $\mathrm{d}+{ }^{3} \mathrm{He} \rightarrow \alpha+\mathrm{p}$, but with a lower probability of $\approx 10^{-5} \cdot \mathrm{d}+{ }^{3} \mathrm{He} \rightarrow \gamma+{ }^{5} \mathrm{Li}$ is of interest to determine the fusion power for aneutronic fusion reactions, such as $\mathrm{d}+{ }^{3} \mathrm{He} \rightarrow \alpha+\mathrm{p}^{17,24}$. The broad shape of the 16.4 $\mathrm{MeV}$ gamma-ray interaction with T-GRS is a combination of the intrinsic broadening of the emission at the source and the Compton effect dominated response function of the $\mathrm{LaBr}_{3}$ scintillator at these energies ${ }^{17}$. 16.4 $\mathrm{MeV}$ gamma-rays are barely detected by the HpGe, due to the low detection efficiency of this instrument in the $\mathrm{E}_{\gamma}>10 \mathrm{MeV}$ range (see figure $\mathrm{II}$ ), which reveals the need for T-GRS also for fusion power measurements, particularly when the HpGe is chosen as the V-GRS for gammaray Doppler broadening measurements.

\section{v. CONCLUSIONS}

A tangential gamma-ray spectrometer (T-GRS) has been developed for the Joint European Torus (JET). The detector is based on the $\mathrm{LaBr}_{3}$ spectrometer and observes the plasma along a tangential line of sight (LOS) that passes $\approx 30 \mathrm{~cm}$ below the magnetic axis in the poloidal plane. A data acquisition system digitizes individual pulses from the detector and above a threshold set by the user. A pulse height spectrum in arbitrary energy and time windows is built after each discharge. The instrument LOS is equipped with a $\mathrm{LiH}$ attenuator, which makes gamma-ray measurements possible in deuteriumtritium plasmas at neutron rates up to a few $10^{18} \mathrm{n} / \mathrm{s}$ and also provides a neutron attenuation factor up to a factor $\approx 900$ in deuterium. Measurements from recent deuterium experiments at JET show that T-GRS can resolve lines from fast ion reactions separated by few hundreds 


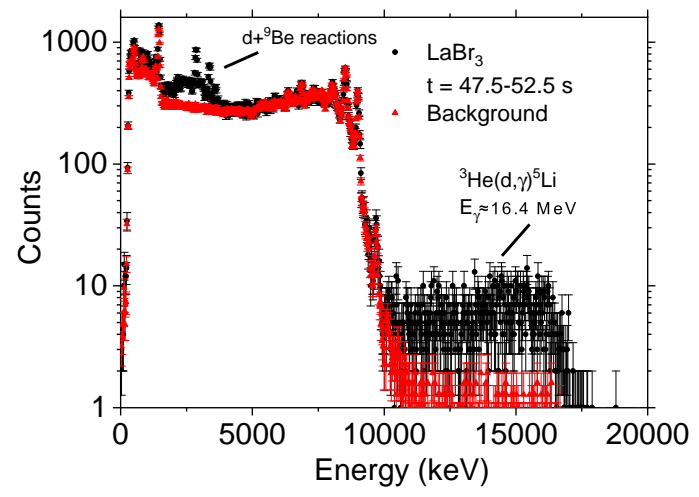

FIG. 5. Gamma-ray spectrum measured by the tangential $\mathrm{LaBr}_{3}$ (bottom) detectors for JET discharge \#95680 in the gamma-ray energy range up to $20 \mathrm{MeV}$ and in the time window $\mathrm{t}=47.5$ to $52.5 \mathrm{~s}$. Events due to the neutron background are indicated by red triangles. The high energy structure due to the interaction of $16.4 \mathrm{MeV}$ gamma-rays born from the $\mathrm{d}+{ }^{3} \mathrm{He} \rightarrow \gamma+{ }^{5} \mathrm{Li}$ reaction is indicated, together with lines from $\mathrm{d}+{ }^{9} \mathrm{Be}$ reactions (see figure IV for details).

$\mathrm{keV}$ in the $\mathrm{MeV}$ range and can detect the $\mathrm{E}_{\gamma}>10 \mathrm{MeV}$ emission from fusion reactions. Due to its line of sight, T-GRS provides complementary information to those obtained from the vertical GRS and the JET gamma-ray cameras, in both the position and velocity space. The instrument is expected to be one of the main diagnostics for studies of confined alpha particles in the forthcoming JET deuterium-tritium campaign.

\section{ACKNOWLEDGEMENTS}

This work has been carried out within the framework of the EUROfusion Consortium and has received funding from the Euratom research and training programme 2014-2018 and 2019-2020 under Grant Agreement No. 633053. The views and opinions expressed herein do not necessarily reflect those of the European Commission. This scientific work was also supported by Polish Ministry of Science and Higher Education within the framework of the scientific financial resources in the years 2015-2020 allocated for the realization of the international co-financed project.

\section{DATA AVAILABILITY STATEMENT}

The data that support the findings of this study are available from the corresponding author upon reasonable request.

${ }^{1}$ Emmanuel Joffrin, Sadrilla Abduallev, Mitul Abhangi, P Abreu, V Afanasev, M Afzal, KM Aggarwal, T Ahlgren, L Aho-Mantila, N Aiba, et al. Nucl. Fusion, 59(11):112021, 2019.

${ }^{2}$ RJ Dumont, J Mailloux, V Aslanyan, M Baruzzo, CD Challis, I Coffey, A Czarnecka, E Delabie, Jacob Eriksson, J Faustin, et al. Nucl. Fusion, 58(8):082005, 2018.
${ }^{3}$ J Figueiredo, A Murari, C Perez Von Thun, D Marocco, M Tardocchi, F Belli, M García Muñoz, A Silva, T Craciunescu, P Blanchard, et al. Rev. Sci. Instrum., 89(10):10K119, 2018.

${ }^{4} \mathrm{M}$ Salewski, M Nocente, B Madsen, I Abramovic, M Fitzgerald, G Gorini, PC Hansen, WW Heidbrink, AS Jacobsen, T Jensen, et al. Nucl. Fusion, 58(9):096019, 2018.

${ }^{5}$ M Nocente, A Dal Molin, N Eidietis, L Giacomelli, G Gorini, Y Kazakov, E Khilkevitch, V Kiptily, M Iliasova, A Lvovskiy, et al. Plasma Phys. Control. Fusion, 62(1):014015, 2019.

${ }^{6}$ D Rigamonti, A Broslawski, A Fernandes, J Figueiredo, L Giacomelli, G Gorini, M Gosk, G Kaveney, V Kiptily, S Korolczuk, et al. Rev. Sci. Instrum., 89(10):10I116, 2018.

${ }^{7}$ M Nocente, D Rigamonti, V Perseo, M Tardocchi, G Boltruczyk, A Broslawski, A Cremona, G Croci, M Gosk, V Kiptily, et al. Rev. Sci. Instrum., 87(11):11E714, 2016.

8 Marco Tardocchi, M Nocente, I Proverbio, VG Kiptily, P Blanchard, Sean Conroy, M Fontanesi, G Grosso, K Kneupner, E Lerche, et al. Phys. Rev. Letters, 107(20):205002, 2011.

${ }^{9} \mathrm{M}$ Nocente, M Tardocchi, I Chugunov, RC Pereira, T Edlington, AM Fernandes, D Gin, G Grosso, V Kiptily, A Murari, et al. Rev. Sci. Instrum., 81(10):10D321, 2010.

${ }_{10} \mathrm{M}$ Nocente, M Tardocchi, A Olariu, S Olariu, RC Pereira, IN Chugunov, A Fernandes, DB Gin, G Grosso, VG Kiptily, et al. IEEE Trans. Nucl. Sci., 60(2):1408-1415, 2013.

${ }^{11}$ VG Kiptily, FE Cecil, and SS Medley. Plasma phys. control. fusion, 48(8):R59, 2006.

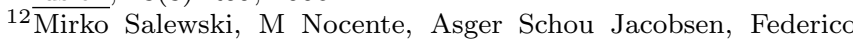
Binda, C Cazzaniga, Göran Ericsson, Jacob Eriksson, G Gorini, Carl Hellesen, Anders Hjalmarsson, et al. Nucl. Fusion, 57(5):056001, 2017.

${ }^{13} \mathrm{C}$ Cazzaniga, M Nocente, M Tardocchi, M Rebai, M Pillon, F Camera, A Giaz, L Pellegri, and G Gorini. Nucl. Instrum. Meth., 778:20-25, 2015.

${ }^{14}$ Ye O Kazakov, J Ongena, JC Wright, SJ Wukitch, E Lerche, MJ Mantsinen, D Van Eester, T Craciunescu, VG Kiptily, Y Lin, et al. Nature Physics, 13(10):973-978, 2017.

${ }^{15}$ Rita C Pereira, Ana M Fernandes, André Neto, Jorge Sousa, Carlos AF Varandas, João Cardoso, Carlos MBA Correia, Marco Tardocchi, Massimo Nocente, Giuseppe Gorini, et al. IEEE Trans. Nucl. Sci., 58(4):1531-1537, 2011.

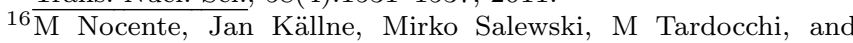
G Gorini. Nucl. Fusion, 55(12):123009, 2015.

${ }^{17}$ Massimo Nocente, Marco Tardocchi, Robin Barnsley, Luciano Bertalot, Benoît Brichard, Gabriele Croci, Giorgio Brolatti, L Di Pace, A Fernandes, Luca Giacomelli, et al. Nucl. Fusion, 57(7):076016, 2017

${ }^{18}$ Marian Curuia, Teddy Craciunescu, Sorin Soare, Vasile Zoita, Viorel Braic, David Croft, Ana Fernandes, Joao Figueiredo, Victor Goloborodko, Giuseppe Gorini, et al. Fusion Eng. Des. 123:749-753, 2017.

${ }^{19}$ D Rigamonti, M Nocente, L Giacomelli, M Tardocchi, M Angelone, A Broslawski, C Cazzaniga, J Figueiredo, G Gorini V Kiptily, et al. JINST, 12(10):C10007, 2017.

${ }^{20}$ Mirko Salewski, M Nocente, G Gorini, Asger Schou Jacobsen, VG Kiptily, Søren Bang Korsholm, Frank Leipold, Jens Madsen, D Moseev, Stefan Kragh Nielsen, et al. Nucl. Fusion, 55(9):093029, 2015.

${ }^{21}$ Yevgen Kazakov, Massimo Nocente, Mervi Mantsinen, Jozef Ongena, Yuriy Baranov, Teddy Craciunescu, Mykola Dreval, Remi Dumont, Jacob Eriksson, Jeronimo Garcia, et al. Nucl. Fusion, 2020.

${ }^{22}$ Massimo Nocente, Ye O Kazakov, J Garcia, VG Kiptily, Jozef Ongena, Mykola Dreval, Michael Fitzgerald, Sergei E Sharapov, Z Stancar, Henri Weisen, et al. Nucl. Fusion, 60(12):124006, 2020.

${ }^{23}$ Panontin E et al. These Proceedings.

${ }^{24} \mathrm{SE}$ Sharapov, Torbjörn Hellsten, VG Kiptily, T Craciunescu, Jacob Eriksson, M Fitzgerald, J-B Girardo, V Goloborodko, Carl Hellesen, Anders Hjalmarsson, et al. Nucl. Fusion, 56(11):112021, 2016. 


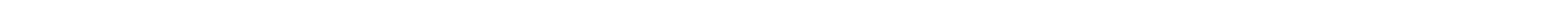




\section{V-GRS}

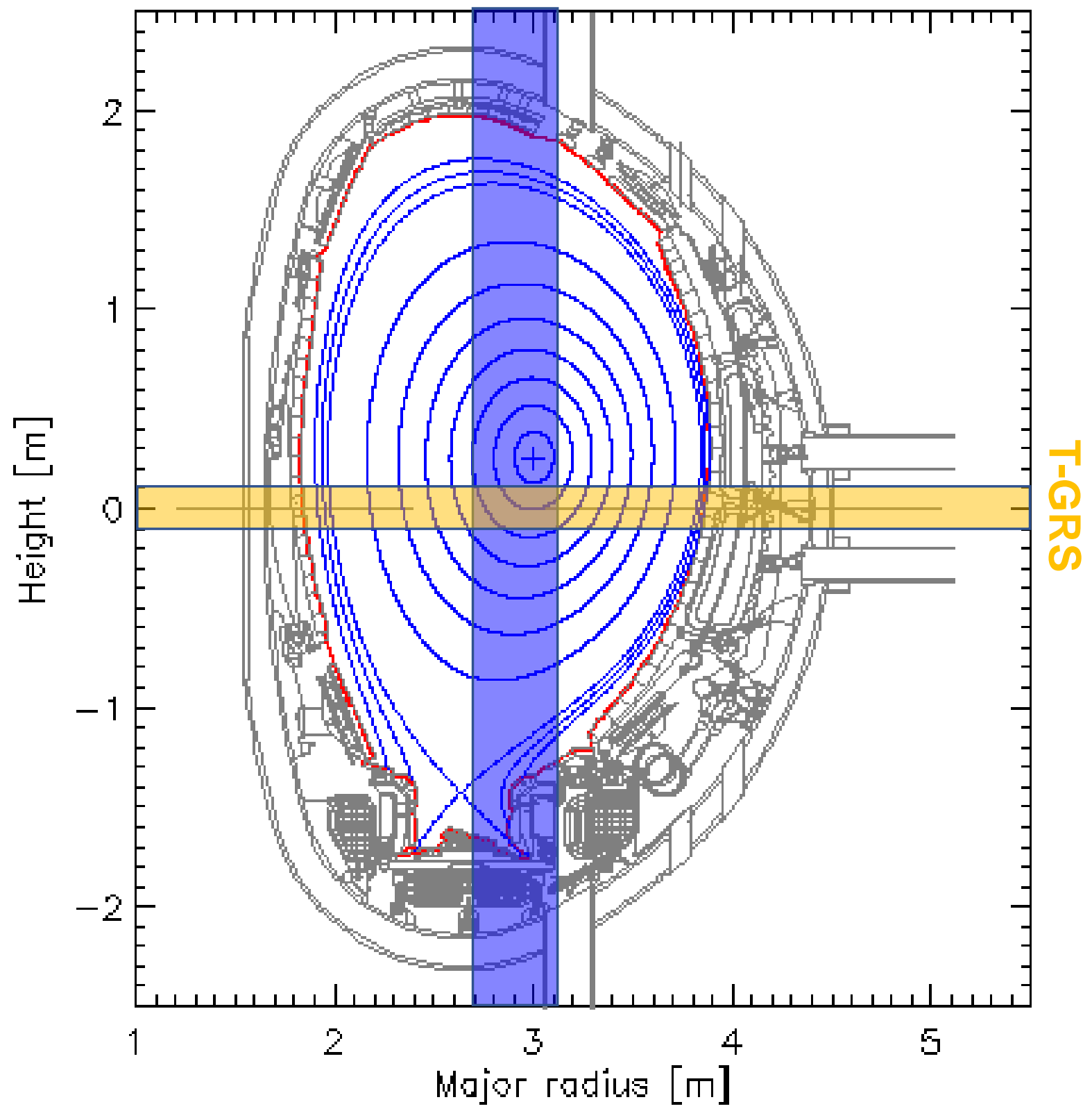



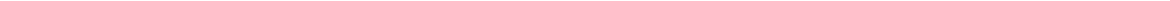


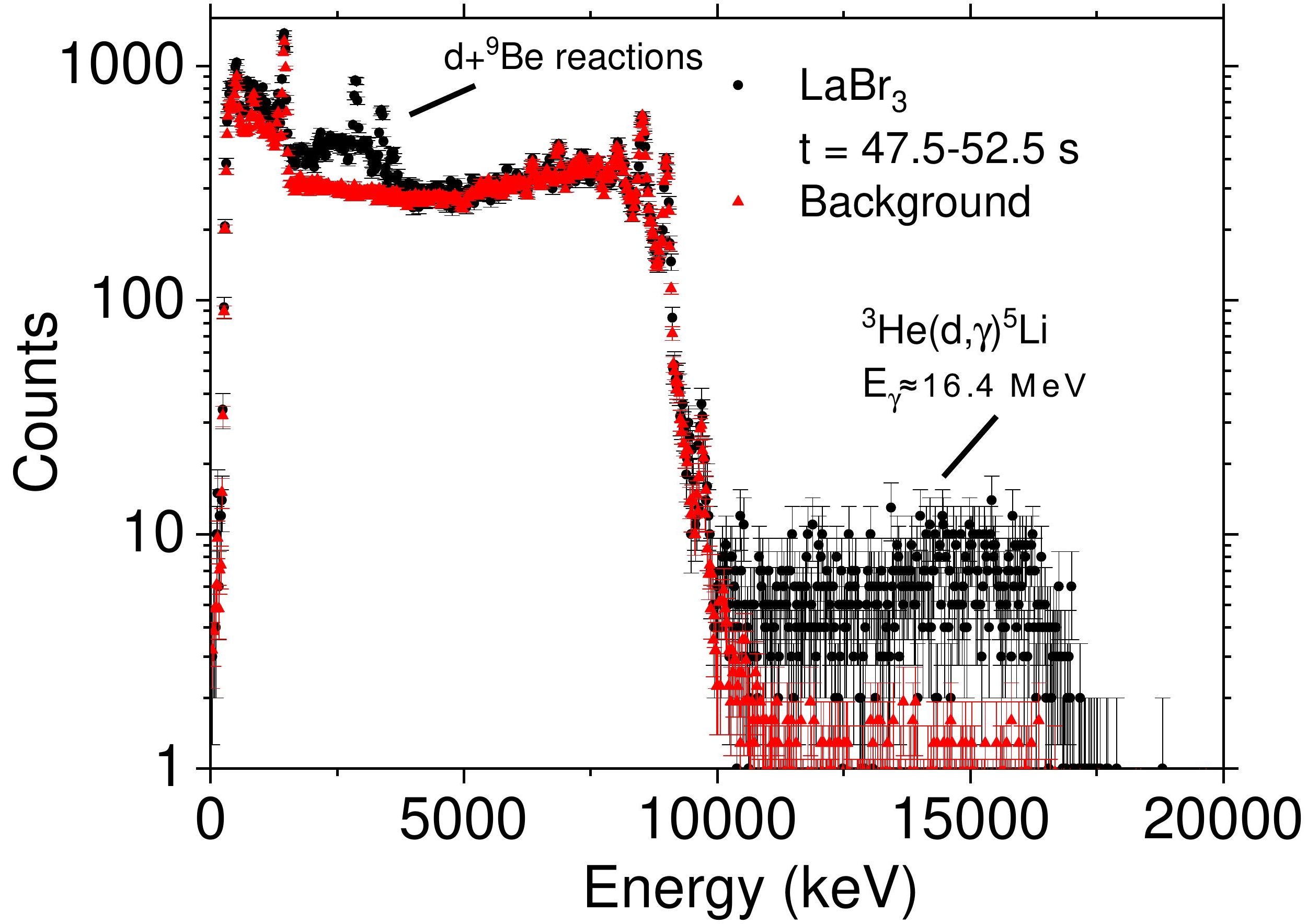

